\title{
An Eco-Concerned Development of a Fast, Precise and Economical Spectrophotometric Assay for the Antiviral Drug Simeprevir based on Ion-Pair Formation
}

\author{
Sabrein H. Mohamed ${ }^{1,2}$, *(D), Yousry M. Issa ${ }^{2} \mathbb{D}$, Alyaa I. Salim ${ }^{3(\mathbb{D}}$ \\ 1 Chemistry Department, College of Science, Jouf University, P. O. Box 2014, Sakaka, Saudi Arabia; sharby@ju.edu.sa \\ (S.H.M.); \\ 2 Chemistry Department, Faculty of Science, Cairo University, Giza, 12613, Egypt; yousry@ sci.cu.edu.eg (Y.M.I.); \\ 3 Faculty of Engineering and Applied Science, Nile University, Giza, Egypt.; asalim@nu.edu.eg (A.I.S.); \\ * Correspondence: sabrein_harbi@yahoo.com;
}

Scopus Author ID 56345842200

Received: 10.01.2021; Revised: 6.02.2021; Accepted: 8.02.2021; Published: 13.02.2021

\begin{abstract}
Simeprevir sodium (SMV) is one of the antiviral drugs used for the treatment of virus C. The current strategy develops and validates a new eco-concerned tool for its quantification in the pure and pharmaceutical formulations. Sulfonephthalein acid dyes were used for this purpose, applying visible analyses based on ion-pair formation. A linear relation between the absorbed signal and the drug concentration is obtained up to $67.0 \mu \mathrm{g} \mathrm{mL}^{-1}$ with $\mathrm{r}^{2}$ of $0.9989-0.9999$. The measurement is carried out at 410, 415, 410, and $403 \mathrm{~nm}$ for bromocresol green, bromoxelenol blue, bromothymol blue, and bromocresol purple, respectively, in dichloromethane as a solvent. The drug structure was confirmed utilizing different tools; mass spectrometry, FT-IR, 1H NMR, and thermal analysis. Association, formation constants, molar absorptivity, and free energy change for SMV-ion-pairs were calculated. The limit of detection reaches $50.0 \mathrm{ng} \mathrm{mL}^{-1}$ with a quantification limit of $180.0 \mathrm{ng} \mathrm{mL}^{-1}$. The recovery values are $96.44-104.39 \%$, with a relative standard deviation $0.15-1.37 \%$. For confirmation of the obtained results, they were statistically compared with a previously published HPLC method utilizing t- and F- tests.
\end{abstract}

Keywords: simeprevir sodium; hepatitis C virus; sulfonephthalein acid dyes; visible spectrophotometry.

(C) 2021 by the authors. This article is an open-access article distributed under the terms and conditions of the Creative Commons Attribution (CC BY) license (https://creativecommons.org/licenses/by/4.0/).

\section{Introduction}

Hepatitis $\mathrm{C}$ is one of the most widely recognized viral liver diseases (after hepatitis B) and is brought about by the hepatitis $\mathrm{C}$ virus (HCV) [1]. Chronic HCV infection is common worldwide that affects a large proportion of the world's population, causing significant morbidity and mortality. Its infection affects approximately 185 million people globally, and it is the reason for 250,000 deaths annually [2].

This virus is an enveloped virus sized from 30 to $60 \mathrm{~nm}$, and it was discovered in 1989. It is a positive, single-stranded RNA virus in the Flaviviridae family with a genome coding for 10 proteins, among which protease NS3-4A and polymerases NS5A/NS5B which have been identified as druggable targets [3-5]. The target virus replications mainly in the liver and leads to serious liver disease, starting with fibrosis and subsequently gradually developing to cirrhosis, hepatocellular carcinoma, and liver failure [5-9]. There are about six HCV genotypes and more than 50 subtypes. The virion has a positive single-stranded RNA genome of 9.5 
kilobases, Fig. 1 [6,10-12]. The genomic arrangement has been resolved, including structural and non-structural regions, Fig. 1 [3].

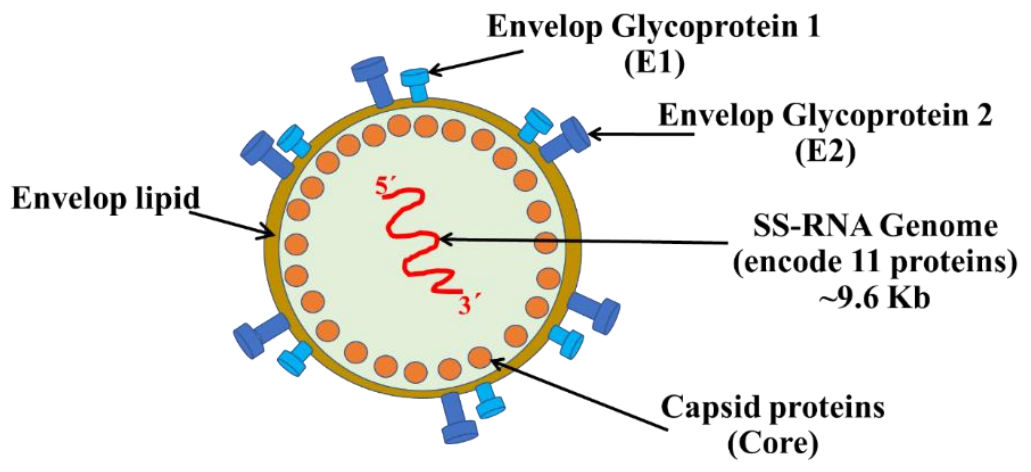

(a)

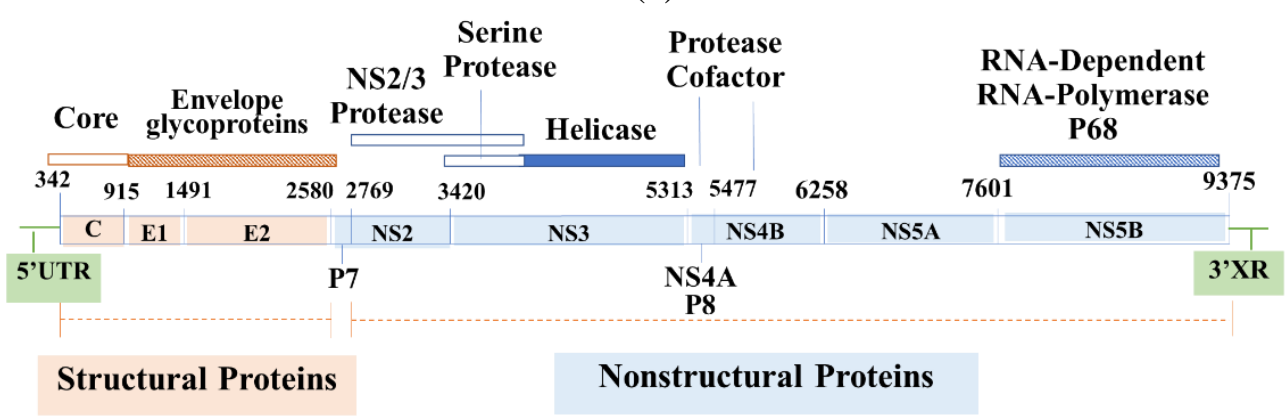

(b)

Figure 1. Model structure of Hepatitis $C$ virus (a) and schematic diagram of the hepatitis $C$ virus genome (b).

$\mathrm{HCV}$ is an asymptomatic and slowly progressive disease developing over10-20 years. It is found that in some cases, hepatitis $\mathrm{C}$ can stay asymptomatic even after significant liver damage has occurred [1]. Up to 2011; the standard of care for the treatment of its infection is consisted of the combination of peginterferon (Peg-IFNa) and ribavirin (RBV), with or without a first-generation protease inhibitor achieving a sustained virological response (SVR) rate of $80-90 \%$ in patients infected with genotype 2 or $3 \mathrm{HCV}$ and of $40-50 \%$ in genotype $1 \mathrm{HCV}-$ infected patients $[1,2,4]$. Moreover, this therapy might be ineffectively endured and can cause serious unfavorable side effects during the treatment period. In late 2013 and early 2014, simeprevir was obtained regulatory approval to treat chronic HCV genotype 1 infection as a component of combination antiviral therapy 8 in multiple countries, offering the first possibility for all-oral treatment regimens [13-16].

Simeprevir Regimens achieve SVR rates of over $90 \%$ in patients with HCV genotype 1 infection during phase II and III trials [7] and in all patient populations, including difficult to treat patients with cirrhosis, human immunodeficiency virus HIV co-infection, and previous non-responders [14].

Simeprevir (SMV, also referred to as TMC 435) is a novel, oral, selective, highly potent, second-generation and non-structural protein 3A/4 (NS3/4A) protease inhibitor $[1,2,17,18]$. It is known that protease inhibitors inhibit viral replication through selectively binding to viral proteases such as NS3/4A and blocking proteolytic cleavage of protein precursors, which are vital for the production of infectious viral particles [19].

Simeprevir sodium (SMV); Sodium (cyclopropanesulfonyl) [(1R,4R,6R,7Z,15R,17R) -17-(\{7-methoxy-8-methyl-2-[4-(propan-2-yl)-1,3-thiazol-2-yl]quinolin-4-yl\}oxy)-13- 
methyl-2,14-dioxo-3,13-diazatricyclo[13.3.0.0^\{4,6\}] octadec-7-ene-4-carbonyl]azanide, has a chemical formula $\mathrm{C}_{38} \mathrm{H}_{46} \mathrm{~N}_{5} \mathrm{NaO}_{7} \mathrm{~S}_{2}$ with a molecular weight of $771.924 \mathrm{~g} \mathrm{~mol}^{-1}$. It is a white powder very slightly soluble in ethanol, practically insoluble in propylene glycol and water, slightly soluble in acetone and soluble in dichloromethane [17,20].

SMV; chemically synthesized, is a single enantiomer with five chiral centers with fixed configurations and containing one stereogenic center. It is amphiprotic with an acidic sulfonyl carboxamide group and a basic thiazole moiety, Scheme 1 [19].

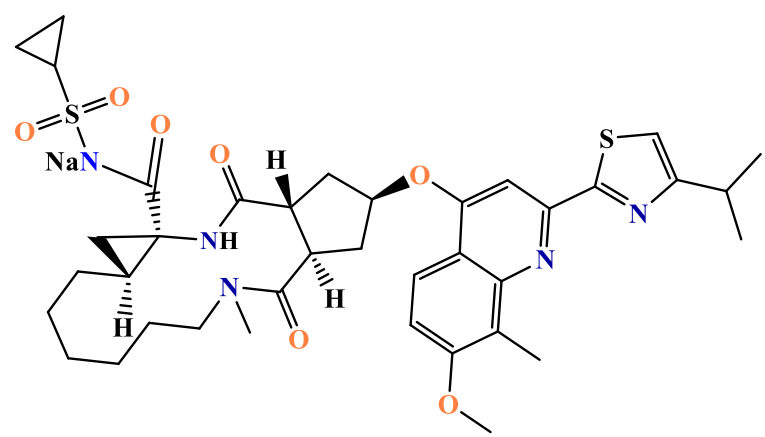

Scheme 1. Plain structural formula of simeprevir sodium.

Because of the high number of infected people worldwide by hepatitis $\mathrm{C}$, it is essential to create a suitable analytical method to assure such drugs in different pharmaceutical dosage forms.

Different analytical techniques are the heart of drug development have been employed in quality control laboratories for simultaneous determination of active ingredients in such dosage forms. UV-visible spectrophotometric methods are the most frequently used for analytical purposes in simultaneous determinations because of the simplicity of the procedure, availability of instruments, low cost, sensitivity, accuracy, and selectivity [20].

According to the literature review and the authors' knowledge, there are few reported articles in the published literature concerning the analysis of SMV due to its recent introduction into the pharmaceutical markets. They include liquid chromatographic methods for its analysis utilizing Photodiode Array (PDA) Detector [21], tandem mass detection [1,4], UV detection [13,22], diode array detection [23] and fluorescence detection [24], spectrofluorimetric methods [25-27] and UV-spectrophotometric methods [20] and our own published UVspectrophotometric method [17].

Simple spectrophotometric strategies did not take a huge part of the cake in the measurement of SMV. Literature survey revealed that there is no previously published work devoted to the determination of SMV based on sulfonephthalein acid dyes as a coloring agent. Accordingly, the present study's main aim is to propose the first ion-pair based colorimetric method for its quantification. Thus, a simple, cost-effective, and extraction-free spectrophotometric method has been developed and validated to determine SMV in bulk and pharmaceutics. The developed method was validated for linearity, range, accuracy, precision, the limit of detection (LOD), and limit of quantitation (LOQ)

Two parts of determinations, one is for the physical analysis and the other for the quantitative determination. The physical analysis includes FT-IR, NMR, mass spectral, and thermal analyses. The quantitative analysis is based on the ion-pair formation between SMV and some sulfonephthalein acid dyes bromothymol blue (BTB), bromocresol purple (BCP), bromocresol green (BCG), and bromoxelenol blue (BXB) in dichloromethane as a solvent. 


\section{Materials and Methods}

\subsection{Apparatus.}

Jenway 6105 UV/Visible single-beam spectrophotometer with a 200-800 $\mathrm{nm}$ range furnished with quartz cells of $1.0 \mathrm{~cm}$ optical path length. All weighing was performed on a Scientech SA 210 digital balance.

Infrared absorption spectroscopy, mass spectrometry, Thermal analysis, and nuclear magnetic resonance were performed in the Micro Analytical Center, Faculty of Science, Cairo University, Giza, Egypt. Infrared (IR) absorption spectra were carried out by applying the $\mathrm{KBr}$ disc technique utilizing a test scan Shimadzu FTIR spectrometer. Nuclear magnetic resonance ( $\left.{ }^{1} \mathrm{H}-\mathrm{NMR}\right)$ spectra were recorded by Varian $300 \mathrm{MHz}$ NMR spectrometer using deuterated dimethyl sulfoxide ( $\mathrm{D}^{6}$-DMSO) deuterium oxide as solvents and tetramethylsilane as an internal standard. Mass spectra were recorded by Q 1000 EX GCMS Shimadzu (Japan) spectrometer at $70 \mathrm{eV}$ and $100 \mu \mathrm{A}$ energy using a direct insertion probe. Thermal analysis was carried out by Shimadzu-50 Thermal Analyzer at a heating rate of $10 \mathrm{deg}$. $\mathrm{min}^{-1}$ in the range of ambient to $600^{\circ} \mathrm{C}$ using Elementer Vario EL III.

\subsection{Materials and reagents.}

In this work, all chemicals and reagents used were of the highest purity available. Dichloromethane was obtained from Sigma-Aldrich (Germany). Bromocresol green (BCG), Bromocresol purple (BCP), bromothymol blue (BTB), and Bromoxylenol blue (BXB) were purchased from BDH Limited, Poole (England). Simeprevir sodium (SMV) powder and Olysio $^{\circledR}$ Capsules (150 mg SMV/capsule) were produced by Janssen pharmaceutical organization.

\subsection{Solutions.}

$39.59 \mathrm{mg}$ of SMV reference material was accurately weighed and transferred into 50 $\mathrm{mL}$ volumetric flask, washed previously with dichloromethane. The volume was completed to $50 \mathrm{~mL}$ dichloromethane to obtain a stock solution of $1.0 \times 10^{-3} \mathrm{~mol} \mathrm{~L}^{-1}$.

17.45, 18.50, 15.60, and $14.21 \mathrm{mg}$, of BCP, BCG, BTB, and BXB powders, respectively, were weighed accurately and dissolved in dichloromethane, and the final volume was made up to $250 \mathrm{~mL}$ with dichloromethane to obtain standard stock solutions of $1.0 \times 10^{-3}$ mol L ${ }^{-1}$ of each sulfonephthalein acid dye.

\subsection{Pharmaceutical formulations.}

Ten Olysio ${ }^{\circledR}$ capsules were accurately weighed. An amount equivalent to one capsule, equivalent to $150 \mathrm{mg}$ SMV, was dissolved in dichloromethane as a solvent. The solution was filtered. The same solvent washed the residue to guarantee that the main active ingredient was dissolved totally. The volume was completed to $50 \mathrm{~mL}$ using the same solvent. Then necessary dilutions of the filtrate were made with dichloromethane to obtain different SMV concentrations. The SMV content of tested capsules was calculated using the newly developed spectrophotometric methods. 


\subsection{Simplified mini-scale spectrophotometric method.}

2.5.1. Ion-pair reactions with sulfonephthalein acid dyes.

Aliquots of $0.2-1.4 \mathrm{~mL}$ of $1.0 \times 10^{-3} \mathrm{~mol} \mathrm{~L}^{-1} \mathrm{SMV}$ standard solution in case of BCG or $5.0 \times 10^{-4} \mathrm{~mol} \mathrm{~L}^{-1}$ in case of $\mathrm{BCP}, \mathrm{BTB}$, and $\mathrm{BXB}$ were transferred to $10 \mathrm{~mL}$ measuring flask. Then, to each flask $3.0 \mathrm{~mL} 1.0 \times 10^{-3} \mathrm{~mol} \mathrm{~L}^{-1} \mathrm{BCG}$ or $2.0 \mathrm{~mL} 5.0 \times 10^{-4} \mathrm{~mol} \mathrm{~L}^{-1}$ of BCG, BTB, or BXB, respectively, were added. The total amount of each solution was brought up to $10 \mathrm{~mL}$ with dichloromethane. The absorbance of the formed yellow-colored ion-pairs was measured at $\lambda_{\max } 410,403,410$, and 415 using BTB, BCP, BCG and BXB, respectively, against the reagent as blank that was similarly prepared. All measurements were done at room temperature $\left(25 \pm 2{ }^{\circ} \mathrm{C}\right)$. The procedures were repeated for other analyte aliquots. A calibration curve was estimated by linear regression to calculate the concentration of SMV in the unknown analyte samples.

\subsubsection{Optimum reaction conditions and method validation.}

The effect of different parameters such as the selection of maximum wavelength, the effect of time, concentration of reagent, type of solvent, and stoichiometry of the formed ionpairs were investigated and optimized to obtain the best conditions such as fastness of the formation of the yellow-colored ion-pairs with highest stability and sensitivity.

\subsubsection{The stoichiometry of the formed ion-pairs.}

The stoichiometric ratios of the formed ion-pairs between the studied drug and sulfonephthalein acid dyes were controlled by Job's method of continuous variation [17,20]. A series of solutions were set up by mixing equimolar solutions of the SMV and reagent in varying proportions while keeping the total molar concentration constant. A plot of the absorbance at the maximum wavelength versus the SMV mole-fraction gave a maximum at the molar ratio to be resolved.

\subsubsection{Stability constant of the ion-pairs.}

Stability constants of the ion-pairs (Kf) were determined by substituting the data of continuous variation in equation (1), which was derived for calculating the stability constant spectrophotometrically [28].

$$
\mathrm{Kf}=\left(\frac{\mathrm{A}}{\mathrm{Am}}\right) /\left(\frac{1-\mathrm{A}}{\mathrm{Am}}\right)^{\mathrm{n}+1} \mathrm{C}^{\mathrm{n}} \mathrm{n}^{\mathrm{n}}
$$

Where, Am and A are the observed maximum absorbance and the absorbance value when all the drug present is related, individually. $\mathrm{n}$ is the stoichiometry with which reagent ion-pairs with drug, and $\mathrm{C}$ is the drug's molar concentration at the maximum absorbance.

\subsubsection{Evaluation of association constant and free energy change.}

The association constants of the formed ion-pairs were determined by applying the Benesi-Hildebrand equation [29]. This method depends on the condition that the non-absorbing species of the two reactants must be added in a large excess, 10 folds of the other component concentration.

The constructed calibration curves were used for calculations. The relation was plotted by the Benesi- Hildebrand showed in equation (2) [29]: 


$$
\frac{\left[\mathrm{A}_{\mathrm{o}}\right]}{\left[\mathrm{A}_{\lambda}^{\mathrm{AD}}\right]}=\frac{1}{\varepsilon^{\mathrm{AD}}}+\left(\frac{1}{\mathrm{~K}_{\mathrm{c}}^{\mathrm{AD}} \cdot \varepsilon_{\lambda}^{\mathrm{AD}}}\right) \cdot \frac{1}{\left[\mathrm{D}_{\mathrm{o}}\right]}
$$

As $\left[\mathrm{A}_{\mathrm{o}}\right]$ and $\left[\mathrm{D}_{\mathrm{o}}\right]$ are the total amount of the interacting species.

On plotting the values of $\left[\mathrm{A}_{\mathrm{o}}\right] /\left[\mathrm{A}_{\lambda}^{\mathrm{AD}}\right]$ versus $1 /\left[\mathrm{D}_{\mathrm{o}}\right]$, a straight line was obtained. The slope equal $\left(\mathrm{K}_{\mathrm{c}}^{\mathrm{AD}} \cdot \varepsilon_{\lambda}^{\mathrm{AD}}\right)^{-1}$, and the intercept of this line with the ordinate is $\left(\varepsilon^{\mathrm{AD}}\right)^{-1}$.

The standard free energy, [17] $\Delta \mathrm{G}^{\mathrm{o}}$, of complexation is related with the association constant $\mathrm{K}$ or the stability constant by equation (3):

$$
\Delta \mathrm{G}^{\mathrm{o}}=-2.303 \mathrm{RT} \log \mathrm{K}
$$

Where: $\mathrm{R}$ is the universal gas constant; $1.987 \mathrm{cal} \mathrm{mol}^{-1}$ degree $^{-1}$ and $\mathrm{T}$ is the temperature in kelvin.

\section{Results and Discussion}

\subsection{Characterization of the structural formula of simeprevir sodium.}

\subsubsection{Mass spectrometric analysis.}

A blend of gaseous ions is isolated and distinguished according to their mass to charge ratios $(\mathrm{m} / \mathrm{z})$. They can take the values $M$ or $(M+1)$, whereas $M$ is the molecular weight of the product ion [30]. Mass spectrometry gives the ability to explain the molecular formula and allows assurance of accurate molecular weight. Mass spectrum has elucidated to a great degree important for getting ionization potentials and bond strengths; that for SMV is shown in Fig. 2. As clear in the spectra, the molecular ion peak of SMV was detected and appeared at $\mathrm{m} / \mathrm{z}$ 771.2 ( $\mathrm{m} / \mathrm{z}$ esteems corresponding to the molecular weight).

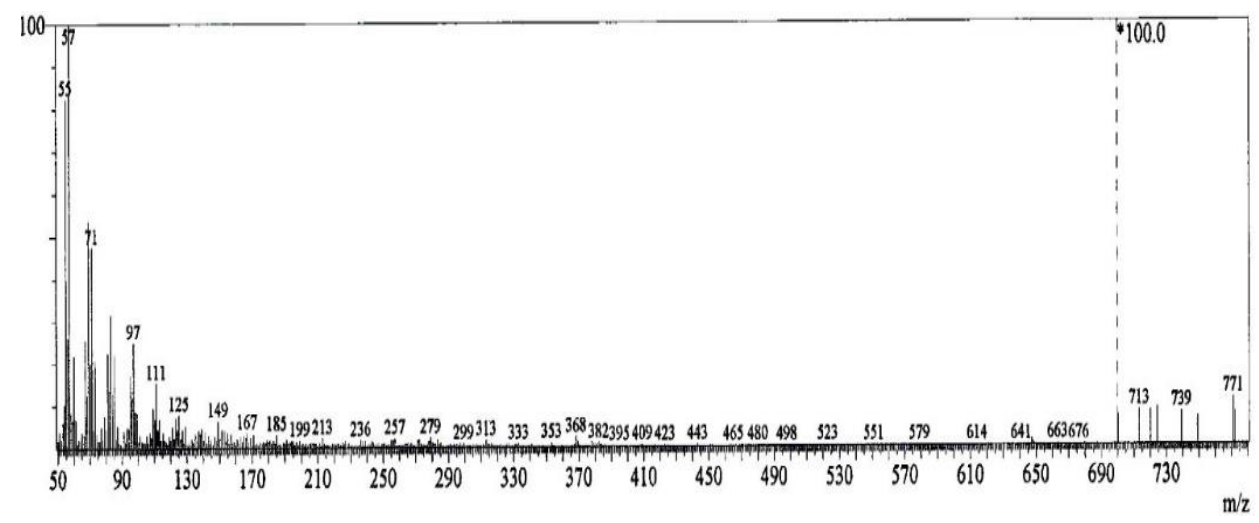

Figure 2. Mass spectrum of simeprevir sodium.

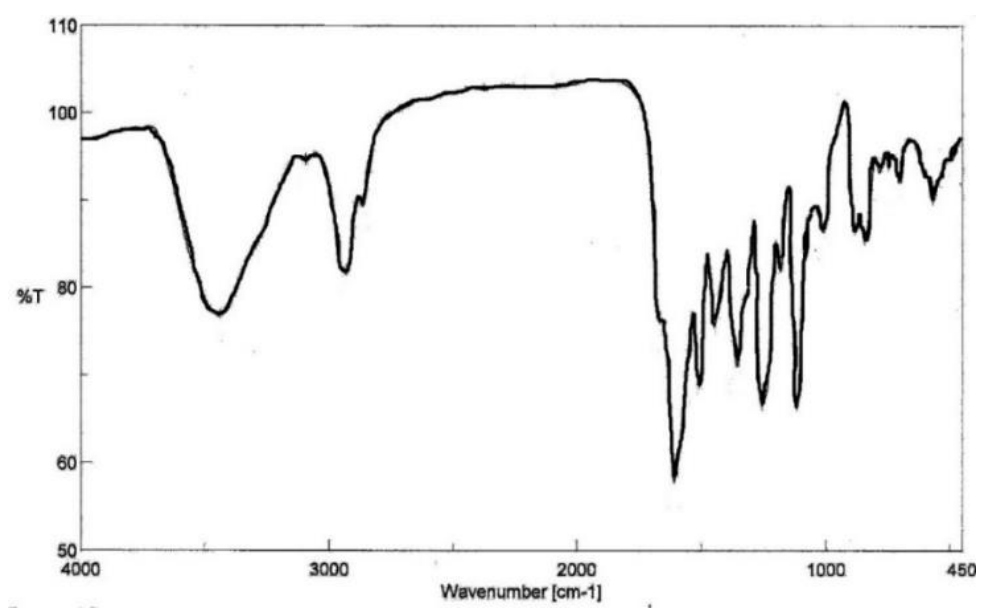

Figure 3. FT-IR absorption spectrum of simeprevir sodium. 
3.1.2. Fourier transforms infrared absorption spectra (FT-IR).

It is a fruitful technique used to represent the different functional groups and helping in the elucidation of the molecular structure of organic compounds [31].

IR spectrum of SMV was recorded in the range $4000-400 \mathrm{~cm}^{-1}$ as $\mathrm{KBr}$ disc, and it is represented in Fig. 3. IR diagnostic bands are shown at 3438, 3094, 2933, 1667, 1609, and $1509,1448 \mathrm{~cm}^{-1}$, which correspond to $\mathrm{N}-\mathrm{H}, \mathrm{C}-\mathrm{H}$ aliphatic, $\mathrm{C}-\mathrm{H}$ aromatic, $\mathrm{C}=\mathrm{O}, \mathrm{C}=\mathrm{C}$ benzene ring, $\mathrm{C}=\mathrm{C}$, and $\mathrm{S}=\mathrm{O}$, respectively.

\subsection{3. ${ }^{1} \mathrm{H}-\mathrm{NMR}$ spectrum.}

Upon using ${ }^{1} \mathrm{H}-\mathrm{NMR}$, we can finish up the number of different types of situations in the molecule and, moreover, which atoms are present in the neighboring groups. Furthermore, determine the distinctions in the number of atoms present in these conditions after chemical reactions 32]. ${ }^{1} \mathrm{H}-\mathrm{NMR}$ spectrum was recorded in DEMSO for SMV; the results are listed in Table 1.

Table 1. ${ }^{1} \mathrm{H}-\mathrm{NMR}$ spectral data of simeprevir sodium.

\begin{tabular}{l|c} 
Assignment & Chemical shift $\boldsymbol{\delta}(\mathbf{p p m})^{*}$ \\
\hline $\mathrm{N}-\mathrm{H}$ & $7.60(\mathrm{~s})$ \\
\hline Aromatic proton of a benzene ring & $6.98-7.91$ \\
\hline $\mathrm{CH}_{3}-$ & $1.33(\mathrm{~d})$ \\
\hline Aromatic proton of a pyrimidine ring & $7.46(\mathrm{~s})$ \\
\hline $\mathrm{H}_{3}-\mathrm{N}$ & $3.14(\mathrm{~s})$ \\
\hline $\mathrm{CH}_{2}-\mathrm{CH}_{2-}$ & $1.22-3.17(\mathrm{~m})$ \\
\hline $\mathrm{H}_{3} \mathrm{C}-\mathrm{O}$ & $3.94(\mathrm{~s})$ \\
$*(\mathrm{~s}):$ singlet; $(\mathrm{m}):$ multiplet, $(\mathrm{d})$ doublet. &
\end{tabular}

\subsubsection{Thermal analysis.}

This technique is extensively used as a part of the pharmaceutical sciences to describe and control drugs, stability, drug-excipient interactions, and purity investigations of raw materials and pharmaceutics [32,33]. Thermogravimetric analysis (TGA) and Differential thermal analysis (DTA) of SMV, Fig. 4, were performed to predict its molecular structure. Weight loss was measured from room temperature up to $600{ }^{\circ} \mathrm{C}$ and the applied heating rate herein was $10^{\circ} \mathrm{C} \mathrm{min}^{-1}$.

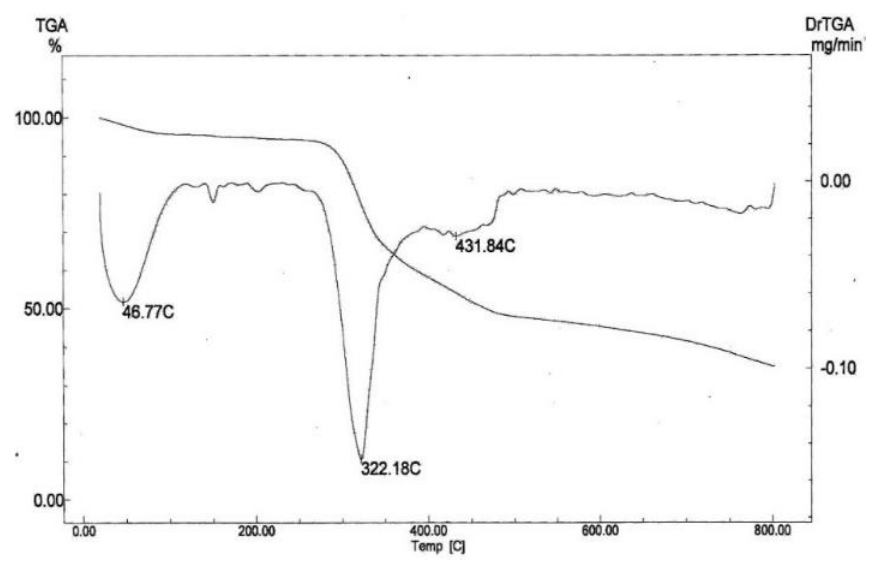

Figure 4. The TGA and DTA plots for simeprevir sodium.

In DTA, the sample heated progressively from room temperature up to $600{ }^{\circ} \mathrm{C}$. TGA curve of SMV shows three thermal degradation steps. The total weight was $2.76 \mathrm{mg}$. The first step of its degradation at $46{ }^{\circ} \mathrm{C}$ corresponds to the loss of water of hydration from the sample 
(around $4.2 \%$ of the sample weight). The second degradation step is observed at $322^{\circ} \mathrm{C}$, which is due to the loss of about $46 \%$ of the sample weight, while the third and final degradation step is shown at $431^{\circ} \mathrm{C}$, which is due to the loss of about $13.6 \%$.

According to the previously mentioned thermal degradation data, the SMV is thermally stable up to $322^{\circ} \mathrm{C}$.

\subsection{Visible spectrophotometry.}

Diverse investigations were carried out to establish the most suitable conditions for the ionpair formation. The spectrophotometric properties of the colored ion-pairs and the following variables' influence on the reactions have been tested.

\subsubsection{Optimization of the mini-scale method.}

As SMV, the nitrogenous drugs are present in a positively charged protonated form, and anionic dyes of the sulfonephthalein group are present mainly in the anionic form [34].

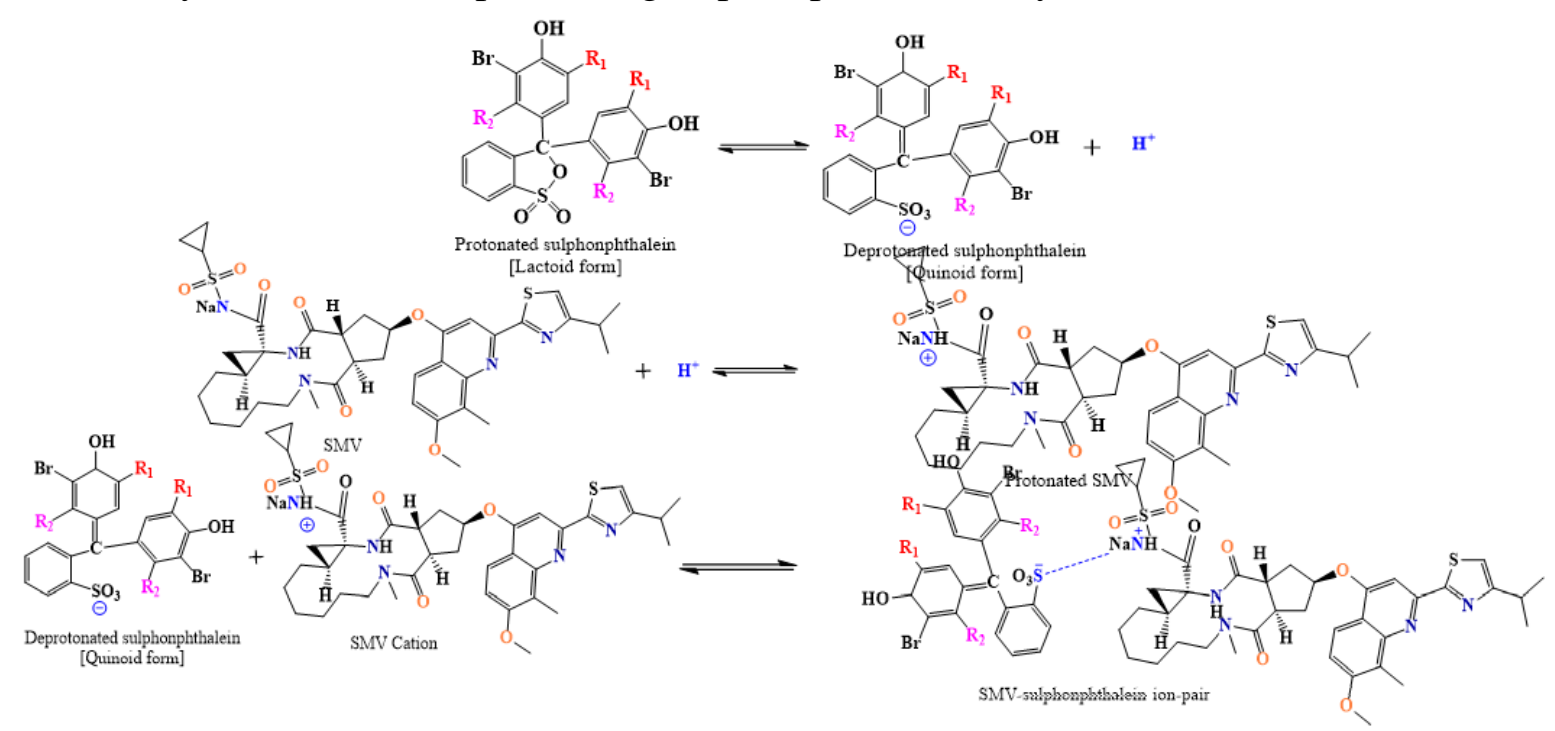

Scheme 2. The proposed mechanism for the reaction between SMV and sulfonephthaleins $(B C G: R 1=B r, R 2=$ $\left.\mathrm{CH}_{3} ; \mathrm{BTB}: \mathrm{R} 1=\mathrm{CH}\left(\mathrm{CH}_{3}\right)_{2}, \mathrm{R} 2=\mathrm{CH}_{3} ; \mathrm{BCP}: \mathrm{R} 1=\mathrm{CH}_{3}, \mathrm{R} 2=\mathrm{H} ; \mathrm{BXB}: \mathrm{R} 1=\mathrm{CH}_{3}, \mathrm{R} 2=\mathrm{CH}_{3}\right)$.

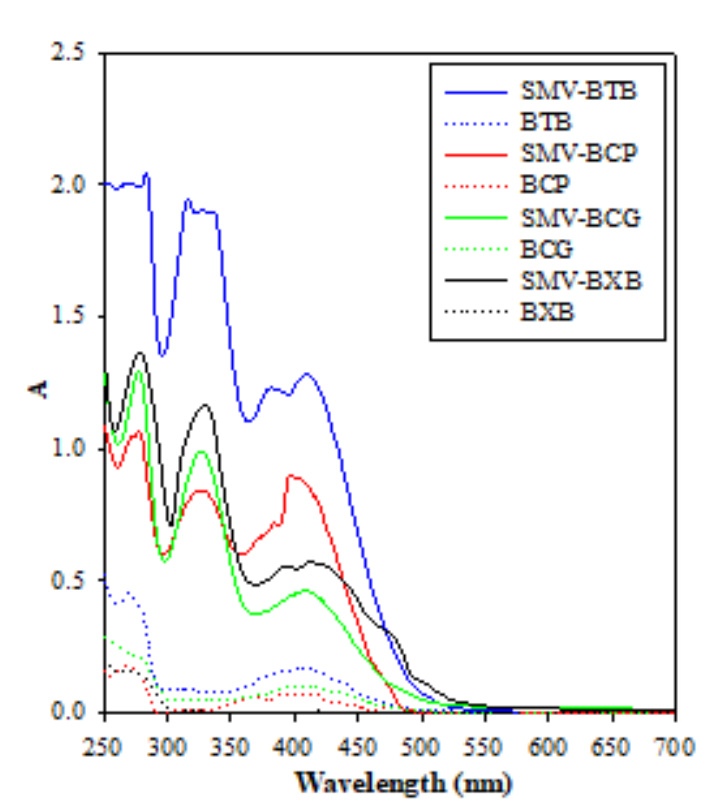

Figure 5. UV-Vis spectra of the SMV-sulfonephthaleins ion-pairs. 
Therefore, when SMV is treated with an acid dye, a yellow ion-pair is formed. The expected proposed pathway for SMV reaction with dyes was postulated in scheme 2, where the basic SMV forms an electrostatic interaction with dyes. The formed binary complex showed a bathochromic shift for SMV spectrum, as appeared in Fig. 5. The formed ion-pairs showed absorption maxima in the visible region at 410, 403, 410, and $415 \mathrm{~nm}$ for SMV-BTB, SMV-BCP, SMV-BCG, and SMV-BXB, respectively. The reagent blanks showed almost negligible absorbance, Fig. 5. In all instances, the absorbance was measured at those $\lambda_{\max }$ against a reagent blank prepared under identical conditions.

The solvent effect was tested in both aqueous and organic solvents. The reaction of SMV and reagents in an aqueous medium do not show good results, where, as increasing reagent concentration, the formed ion-par was destroyed, and therefore, the value of $\varepsilon$ was very small and not accurate. Hence, water could not be utilized as a medium for the direct estimation of the ion-pairs absorbance. Hence, to select the most appropriate organic solvent, several water-miscible and immiscible solvents were examined. Water miscible solvents such as ethanol, methanol, and isopropanol showed no change in color and/or low intensity relative to the immiscible solvents such as benzene, toluene, carbon tetrachloride, dichloromethane, 1.2dichloroethane, chloroform, and ether. In the studied work, the highest reading and negligible blank absorbance were achieved upon using dichloromethane as a solvent.

An optimal quantity of the reagent solution must be included to ensure that it will respond with most of the analyte (SMV) introduced in the test solution. To carry out this test, a series of solutions containing a constant SMV concentration, $38.95 \mu \mathrm{g} \mathrm{mL}^{-1}$, was added to 0$5.0 \mathrm{~mL} 5 \times 10^{-4} \mathrm{~mol} \mathrm{~L}^{-1}$ acid dye solution. The ion-pairs' optimum color intensity was achieved with $2.0 \mathrm{~mL}$ of BTB, BCP, and BXB while it was $3.0 \mathrm{~mL}$ in case of using BCG solution, Fig. 6.

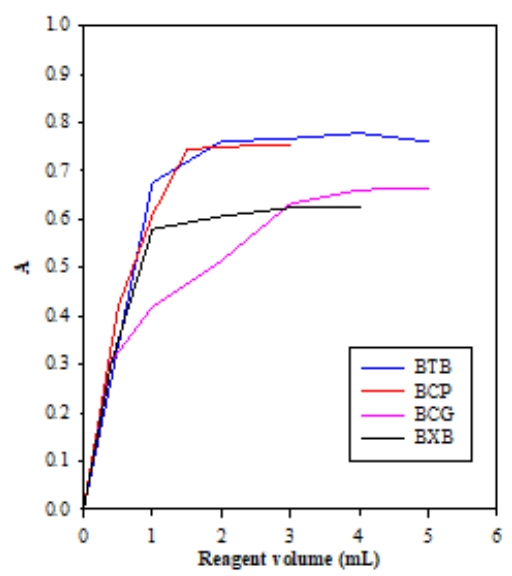

Figure 6. Test for the optimal quantity of the reagent solution $\left(5 \times 10^{-4} \mathrm{~mol} \mathrm{~L}^{-1}\right)$ for forming the ion-pair with $38.95 \mu \mathrm{g} \mathrm{mL}{ }^{-1} \mathrm{SMV}$.

The standing time effect on the ion-pairs formation was investigated to get the ideal conditions for the response. It was researched by enabling the reaction to continue for different time intervals; $1.0-60 \mathrm{~min}$, at room temperature $\left(25 \pm 2{ }^{\circ} \mathrm{C}\right)$. What's more, the ion-pairs' stability was also considered by following the absorption intensity of the formed ion-pairs at different time intervals. Upon mixing the volume of SMV standard solution with the suitable volume of $\mathrm{BTB}, \mathrm{BCP}, \mathrm{BCG}$, or BXB solution, a colored ion-pair was formed in dichloromethane. The absorbance was measured at 410, 403, 410, and $415 \mathrm{~nm}$ upon using BTB, BCP, BCG, and $\mathrm{BXB}$, respectively, as ion-pairing agents against the reagent as a blank. The results ensured 
that the absorbance could be measured after $1 \mathrm{~min}$ from the addition of the reagent solution to the drug solution or at any time until $120 \mathrm{~min}$ at room temperature $\left(25 \pm 2{ }^{\circ} \mathrm{C}\right)$.

The stoichiometry of the reactions was determined using Job's continuous variation method to determine SMV's molar ratio to each of the analytical reagents employed in the ionpair reactions. The ratio (drug : dye) was 1:1 and 1:2 ion-pairs in the case of BCG and was 1:1 in cases of BTB, BCP, and BXB because of the electrostatic attraction between the positively charged protonated $\mathrm{SMV}^{+}$and negatively charged $\mathrm{BTB}^{-}, \mathrm{BCP}^{-}, \mathrm{BCG}^{-}$or $\mathrm{BXB}^{-}$(Fig. 7).

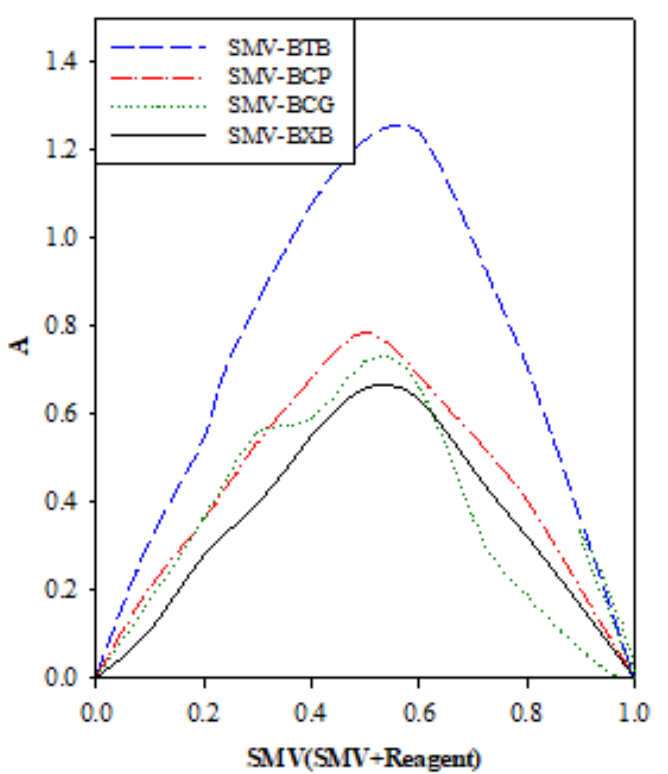

Figure 7. Job's method of continuous variation plots of SMV with BTB, BCP, BCG and BXB ion-pairs.

\subsubsection{Stability study for SMV ion-pairs.}

From the continuous variation method, the formation constant ( $\mathrm{Kf}$ ) of the formed ionpairs could be calculated [28] applying equation (1). The obtained results showed that the formation constants of the formed ion-pairs are high; $8.2 \times 10^{4}-5.7 \times 10^{8} \mathrm{~L} \mathrm{~mol}^{-1}$, indicating the formed ion-pairs' stability, Table 2.

Association constant $\left(\mathrm{K}_{\mathrm{c}}^{\mathrm{AD}}\right)$ is a numerical constant depicting the affinity of binding between two molecules to form an ion-pair. Benesi-Hildebrand method [29] was used to calculate the association constant of SMV ion-pairs with sulfonephthalein dyes. This strategy depends on the prerequisite that one of the reactants' concentrations is substantially higher than the other reactant in the solution. The absorbance of the formed ion-pairs was estimated as a function of varied $[\mathrm{A}]$ when $[\mathrm{D}]>>[\mathrm{A}]$ where $\mathrm{D}$ and $\mathrm{A}$ are the drug and reagent concentrations, respectively applying equation (2).

On plotting the values of $\left[\mathrm{A}_{\mathrm{o}}\right] /\left[\mathrm{A}_{\lambda}^{\mathrm{AD}}\right]$ versus $1 /\left[\mathrm{D}_{\mathrm{o}}\right]$, a straight line was obtained, Fig. 8 , which is described by the following equation:

$$
\begin{array}{ll}
{\left[\mathrm{A}_{0}\right] /\left[\mathrm{A}_{\lambda}^{\mathrm{AD}}\right]=2.39 \times 10^{-5}+1 /\left[\mathrm{D}_{\mathrm{o}}\right]\left(4.37 \times 10^{-9}\right)} & (\mathrm{SMV}-\mathrm{BTB}) \\
{\left[\mathrm{A}_{\mathrm{o}}\right] /\left[\mathrm{A}_{\lambda}^{\mathrm{AD}}\right]=1.09 \times 10^{-4}+1 /\left[\mathrm{D}_{\mathrm{o}}\right]\left(1.03 \times 10^{-9}\right)} & (\mathrm{SMV}-\mathrm{BCP}) \\
{\left[\mathrm{A}_{\mathrm{o}}\right] /\left[\mathrm{A}_{\lambda}^{\mathrm{AD}}\right]=1.56 \times 10^{-4}+1 /\left[\mathrm{D}_{\mathrm{o}}\right]\left(8.81 \times 10^{-9}\right)} & (\mathrm{SMV}-\mathrm{BCG}) \\
{\left[\mathrm{A}_{\mathrm{o}}\right] /\left[\mathrm{A}_{\lambda}^{\mathrm{AD}}\right]=2.77 \times 10^{-5}+1 /\left[\mathrm{D}_{\mathrm{o}}\right]\left(2.97 \times 10^{-8}\right)} & (\mathrm{SMV}-\mathrm{BXB})
\end{array}
$$

The association constants $\left(\mathrm{K}_{\mathrm{c}}^{\mathrm{AD}}\right)$ and the molar absorptivity, $\left(\varepsilon_{\lambda}^{\mathrm{AD}}\right)$ are listed in Table 2. The values of the association constant of the formed ion-pairs reveal the stability of the formed 
ion-pairs. What's more, the standard free energy of complexation $\Delta \mathrm{G}^{\circ}$ is related to the association, or the formation constant was evaluated. The free energy change $\left(\Delta G^{\circ}\right)$ is a thermodynamic parameter that evaluates the suddenness of the compound response. The data showed negative values of the calculated free energy $\left(\Delta \mathrm{G}^{0}\right) ;-5097.27,-6851.86,-5793.06$, and $-4049.71 \mathrm{kcal} \mathrm{mol}^{-1}$ for BTB, BCP, BCG, and BXB, respectively, indicating the stability of these ion-pairs and their spontaneous formation, Table 2.

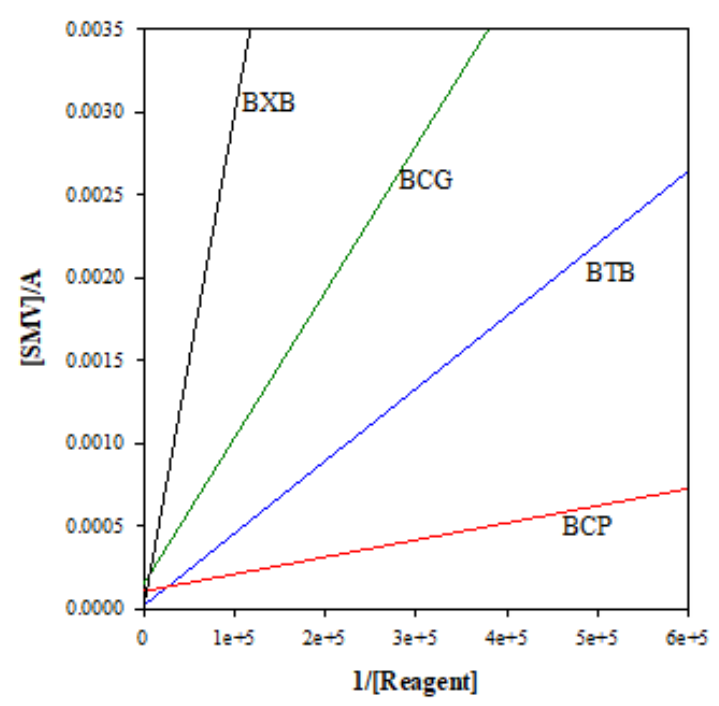

Figure 8. Benesi-Hildebrand plots for SMV-ion-pair with BTB, BCP, BCG and BXB.

Table 2. Association, formation constants, molar absorptivity, and free energy change for SMV-ion-pairs.

\begin{tabular}{|c|c|c|c|c|}
\hline \multirow{2}{*}{ Parameter } & \multicolumn{4}{|c|}{ Reagent } \\
\hline & BCG & BXB & BTB & BCP \\
\hline$\varepsilon_{\max }\left(\mathrm{L} \mathrm{mol}^{-1} \mathrm{~cm}^{-1}\right)$ & $6.4 \times 10^{3}$ & $3.6 \times 10^{4}$ & $4.2 \times 10^{4}$ & $9.2 \times 10^{3}$ \\
\hline 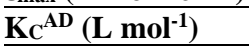 & $1.8 \times 10^{4}$ & $9.3 \times 10^{2}$ & $5.5 \times 10^{3}$ & $1.1 \times 10^{5}$ \\
\hline 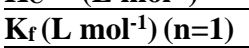 & $1.4 \times 10^{5}$ & $8.2 \times 10^{4}$ & $2.9 \times 10^{5}$ & $2.8 \times 10^{5}$ \\
\hline$(n=2)$ & $5.7 \times 10^{8}$ & - & - & - \\
\hline$\overline{\Delta G\left(\text { kcal mol }^{-1}\right)}$ & -5793.06 & -4049.71 & -5097.27 & -6851.86 \\
\hline
\end{tabular}

\subsection{Analytical performance and method validation.}

The current methods were validated for linearity and range, sensitivity, precision, accuracy, robustness, ruggedness, specificity, and recovery following procedures that reflect the ICH guidelines under the optimal SMV conditions [17,32].

Once the optimal method protocols of the maximum wavelength, solvent, time, and reagent concentration were established, a set of assays to verify its overall performance was carried out. Standard calibration curves for SMV using BTB, BCP, BCG, and BXB were constructed by plotting absorbance as a concentration function, Fig. 9. The statistical parameters for SMV are provided in the regression equation calculated from the calibration graphs, Table 3. The molar absorptivity, Sandell's sensitivities, and correlation coefficients were estimated for each ion-pair. Match with Beer's law was evident in the concentrations up to $60,35,60$, and $67 \mu \mathrm{g} \mathrm{mL}^{-1}$ for BTB, BCP, BCG, and BXB, respectively. The higher molar absorptivity and lower Sandell sensitivity values were $1.27 \times 10^{4}, 1.54 \times 10^{4}, 1.47 \times 10^{4}$, and $1.14 \times 10^{4} \mathrm{~L} \mathrm{~mol}^{-1} \mathrm{~cm}^{-1}$ and $6.06 \times 10^{-2}, 5.0 \times 10^{-2}, 5.26 \times 10^{-2}$ and $6.21 \times 10^{-2} \mu \mathrm{g} \mathrm{cm}^{-2}$ for BTB, BCP, $\mathrm{BCG}$, and BXB, respectively, indicate the good and high sensitivity of the methods. As shown in Table 3, an excellent linear response of absorbance concerning the concentration of SMV was found with the correlation coefficients $\left(\mathrm{r}^{2}\right)$ of 0.9996, 0.9989, 0.9999, and 0.9997 for BTB, $\mathrm{BCP}, \mathrm{BCG}$, and BXB, respectively, indicating good linearity of the calibration curves over the 
concentration range and the small y-intercept values of the regression equations indicating the accuracy of the method.

Keeping in mind the end goal to describe a suitable concentration ranges with minimum error and assess the accuracy in photometric investigation, Ringbom plots [35] for the optimum concentration ranges can be acquired by plotting the photometric data of percent transmittance $(\% \mathrm{~T})$ as ordinates against the logarithm of concentration as abscissas; such curves dependably pass through an inflection as appeared in Fig. 10. Ringbom optimum concentration range values are 15.44-46.32, 7.72-38.59, 15.44-61.66 and 9.17-47.79 $\mu \mathrm{g} \mathrm{mL}^{-1}$ using BTB, BCP, BCG and BXB, respectively.

The limit of detection (LOD) and quantifications (LOQ) was calculated for validation of the analytical procedures [20] according to equations 4 and 5:

$$
\begin{aligned}
& \mathrm{LOD}=3 \mathrm{~s} / \mathrm{m} \\
& \mathrm{LOQ}=10 \mathrm{~s} / \mathrm{m}
\end{aligned}
$$

Where, $\mathrm{s}$ is the standard deviation of recreating calculated values under the same conditions as for the sample analysis without the analyte, and $\mathrm{m}$ is the slope of the calibration plot. Data are tabulated in Table 3, where LOD was determined to be $0.05-0.36 \mu \mathrm{g} \mathrm{mL}^{-1}$ and LOQ were estimated to be $0.18-1.21 \mu \mathrm{g} \mathrm{mL}^{-1}$. Therefore, the proposed methods' sensitivity is high due to the lower values of the detection limits.

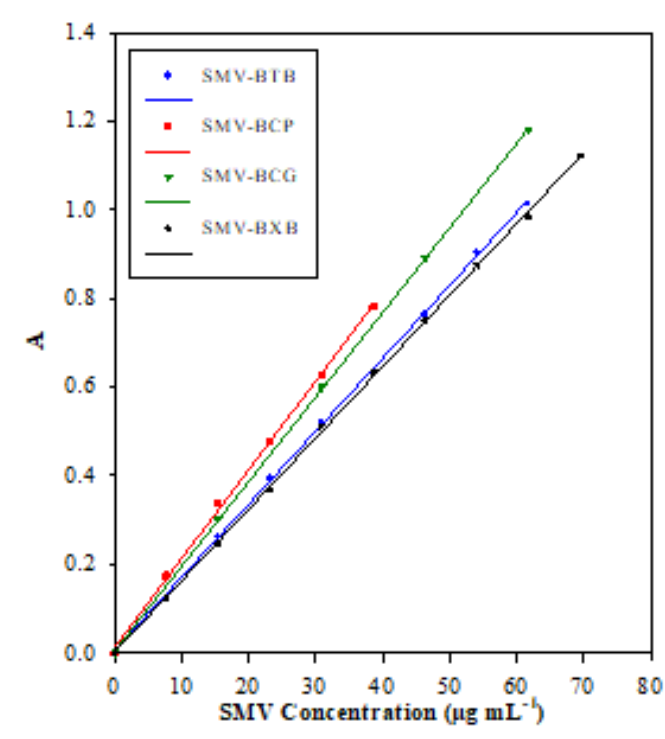

Figure 9. Validity of Beer's law for SMV-ion-pairs with $\mathrm{BTB}, \mathrm{BCP}, \mathrm{BCG}$ and $\mathrm{BXB}$ in dichloromethane.

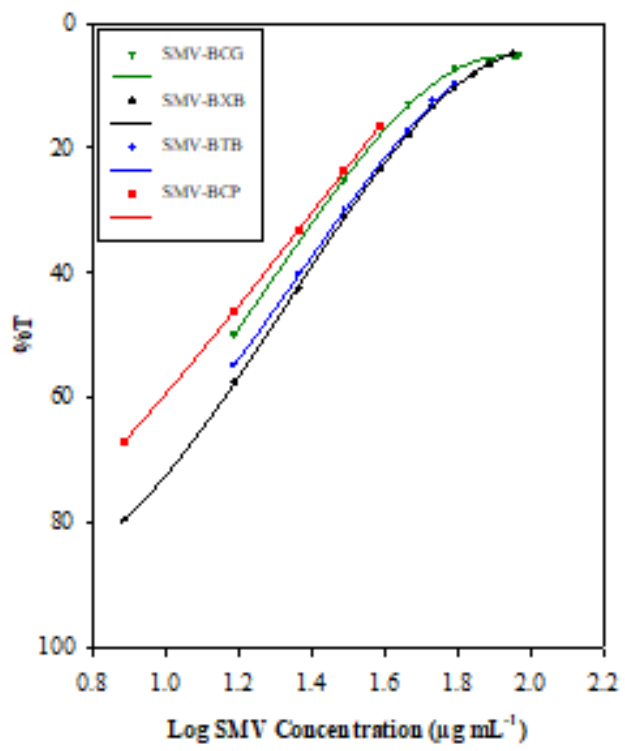

Figure 10. Ringbom plots for SMV-ion-pairs in dichloromethane.

\begin{tabular}{|c|c|c|c|c|}
\hline \multirow[t]{2}{*}{ Parameter } & \multicolumn{4}{|c|}{ Reagents } \\
\hline & BCG & BXB & BTB & $\mathbf{B C P}$ \\
\hline$\lambda_{\max }(\mathbf{n m})$ & 410 & 415 & 410 & 403 \\
\hline Beer's law $\left(\mu \mathrm{g} \mathrm{mL}{ }^{-1}\right)$ & Up to 60 & Up to 67 & Up to 60 & Up to 39 \\
\hline Molar absorptivity $\left(\mathrm{L} \mathrm{mol}^{-1} \mathrm{~cm}^{-1}\right)$ & $1.47 \times 10^{4}$ & $1.24 \times 10^{4}$ & $1.27 \times 10^{4}$ & $1.54 \times 10^{4}$ \\
\hline Sandell sensitivity $\left(\mu \mathrm{g} \mathrm{cm}^{-2}\right)$ & $5.26 \times 10^{-2}$ & $6.21 \times 10^{-2}$ & $6.06 \times 10^{-2}$ & $5.0 \times 10^{-2}$ \\
\hline Ringbom range $\left(\mu \mathrm{g} \mathrm{mL}^{-1}\right)$ & $12.59-39.81$ & $14.13-39.81$ & $15.14-37.15$ & $10.23-32.36$ \\
\hline Limit of detection (LOD) $\left(\mu \mathrm{g} \mathrm{mL}^{-1}\right)$ & 0.36 & 0.13 & 0.09 & 0.05 \\
\hline Limit of quantification (LOQ) $\left(\mu \mathrm{g} \mathrm{mL^{-1 } )}\right.$ & 1.21 & 0.44 & 0.33 & 0.18 \\
\hline Slope $\left(\mathrm{mL} \mu \mathrm{g}^{-1} \mathrm{~cm}^{-1}\right)$ & $1.9 \times 10^{-2}$ & $1.6 \times 10^{-2}$ & $1.7 \times 10^{-2}$ & $2.0 \times 10^{-2}$ \\
\hline Intercept & $4.0 \times 10^{-3}$ & $2.0 \times 10^{-3}$ & $6.0 \times 10^{-3}$ & $1.3 \times 10^{-2}$ \\
\hline Correlation coefficient $\left(\mathbf{r}^{2}\right)$ & 0.9999 & 0.9997 & 0.9996 & 0.9989 \\
\hline Relative standard deviation $($ RSD\% $)(n=3)$ & $0.15-0.35$ & $0.37-0.97$ & $0.19-0.47$ & $0.71-0.96$ \\
\hline
\end{tabular}

Table 3. Analytical characteristics and precision data for the determination of SMV using sulfonphthalein acid 
To gauge the proposed methods' precision and accuracy, solutions containing three distinct concentrations of pure SMV under the described conditions within calibration curve limits were prepared. Four replicates estimations were tested utilizing the calibration method. The mean percent recovery was found to be $97.91-101.96 \%$, accomplishing great accuracy and selectivity, Table 4.

Percentage relative standard deviation (RSD\%), as precision, demonstrating reasonable repeatability (degree of scattering) of the technique and percentage relative error (Er\%) as the accuracy of the recommended method was processed and can be considered to be very satisfactory. By observing the results, the proposed methods are proved to be precise from low RSD\% values, which are $\leq 1.43$ as shown in Table 4 .

Method robustness was assessed by rolling out small incremental changes in the volume of reagents and wavelength at three different drug levels. The effect of these changes on the absorbance of the correlated system was studied. These changes had an irrelevant impact on the results as revealed by little moderate precision esteems expressed as RSD\% (0.17-1.02) for $\mathrm{BTB}, \mathrm{BCP}, \mathrm{BCG}$, and BXB. To check ruggedness, the analysis was done by two analysts, and furthermore by a single analyst performing investigation using three distinctive cuvettes. Intermediate precision expressed as percent RSD was in the range of $0.58-0.97 \%$ showing acceptable ruggedness.

Table 4. Evaluation of precision of the proposed methods in SMV pure samples and Olysio® capsules.

\begin{tabular}{|c|c|c|c|c|c|c|c|c|c|}
\hline \multirow{2}{*}{ 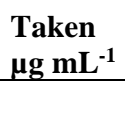 } & \multicolumn{4}{|c|}{ BCG method } & \multirow{2}{*}{$\begin{array}{c}\text { Taken } \\
\mu \mathrm{g} \mathrm{mL} \mathbf{~}^{-1}\end{array}$} & \multicolumn{4}{|c|}{ BXB method } \\
\hline & Recovery \% \pm SD & RSD\% & t-Test & F-test & & Recovery \% \pm SD & RSD\% & t-test & F-test \\
\hline \multicolumn{10}{|c|}{ Pure form } \\
\hline 30.88 & $97.91 \pm 0.34$ & 0.35 & 2.78 & 0.07 & 15.44 & $99.79 \pm 0.37$ & 0.37 & 0.11 & 0.079 \\
\hline 46.32 & $99.02 \pm 0.15$ & 0.15 & 4.12 & 0.01 & 23.16 & $101.96 \pm 1.46$ & 1.43 & 2.30 & 0.59 \\
\hline 61.75 & $99.26 \pm 0.32$ & 0.32 & 2.63 & 0.06 & 30.88 & $100.77 \pm 0.39$ & 0.39 & 1.73 & 0.09 \\
\hline \multicolumn{10}{|c|}{ Olysio $^{\circledR}$ capsules $(150 \mathrm{mg}$ SMV/capsule) } \\
\hline 24.56 & $99.24 \pm 0.24$ & 0.24 & 1.04 & 0.03 & 28.81 & $99.25 \pm 1.14$ & 1.15 & 3.36 & 0.75 \\
\hline 48.01 & $101.05 \pm 0.59$ & 0.58 & 1.29 & 0.20 & 29.99 & $101.85 \pm 0.88$ & 0.86 & 2.08 & 0.45 \\
\hline 59.98 & $99.21 \pm 0.43$ & 0.43 & 1.37 & 0.11 & 59.98 & $96.44 \pm 0.62$ & 0.64 & 3.41 & 0.22 \\
\hline \multicolumn{5}{|c|}{ BTB method } & \multicolumn{5}{|c|}{ BCP method } \\
\hline \multicolumn{3}{|c|}{ Pure form } & & & & & & & \\
\hline 15.44 & $100.12 \pm 0.34$ & 0.34 & 0.37 & 0.07 & 15.44 & $99.89 \pm 0.71$ & 0.71 & 0.06 & 0.29 \\
\hline 30.88 & $99.42 \pm 0.47$ & 0.47 & 0.62 & 0.13 & 23.16 & $101.00 \pm 0.97$ & 0.96 & 2.67 & 0.54 \\
\hline 61.75 & $101.05 \pm 0.19$ & 0.19 & 1.73 & 0.02 & 30.88 & $99.97 \pm 0.74$ & 0.74 & 0.11 & 0.32 \\
\hline \multicolumn{5}{|c|}{ Olysio $^{\circledR}$ capsules (150 mg SMV/capsule) } & & & & & \\
\hline 15.90 & $98.01 \pm 0.39$ & 0.39 & 2.91 & 0.09 & 11.99 & $98.57 \pm 0.62$ & 0.63 & 1.76 & 0.36 \\
\hline 39.59 & $100.33 \pm 0.49$ & 0.49 & 0.84 & 0.14 & 17.99 & $99.87 \pm 0.70$ & 0.70 & 0.01 & 0.40 \\
\hline 55.66 & $99.71 \pm 0.58$ & 0.58 & 0.28 & 0.19 & 29.99 & $99.99 \pm 1.03$ & 1.03 & 0.23 & 0.59 \\
\hline
\end{tabular}

\subsection{Analysis of pharmaceutical formulations.}

It is obvious from the above-mentioned results that the proposed methods gave satisfactory results for SMV estimation in pure forms. To demonstrate the mini-scale approach's applicability, the proposed method was tested for the assay of SMV in Olysio capsules $^{\circledR}$, and a reported method obtained by the HPLC [13] was used as a reference method for the comparison. The detailed techniques for the SMV assurance under investigation in pharmaceutical capsules were plainly discussed in the experimental part. Various concentrations of Olysio ${ }^{\circledR}$ appeared in Table 4. Recovery studies were achieved by the calibration curve method. The latter is within the range of $96.44-101.85 \%$ with RSD 0.24$1.43 \%$, Table 4 . The high percentage recoveries elucidate no interferences from excipients that might be found in different formulations. 


\subsection{Statistical analysis of the obtained data.}

For additional confirmation for the validity of the proposed methods, the results of the developed methods in pure solution and pharmaceutical formulation were statistically compared with the previously reported method obtained by the HPLC [13] using statistical analysis concerning the accuracy (by t-test) and precision (by F-test), Table 4. At 95\% confidence limit for four repeated estimations is listed in Table 4. Obviously, they did not exceed the critical values (4.3 and 39.17 for t- and F-tests, respectively) [25]. This indicates that no significant differences are found between the calculated and theoretical estimations of $\mathrm{t}$-and F-tests, proving the agreement in accuracy and precision.

\section{Conclusions}

A fast, facile ion-pair formation method based on the sulfonephthalein group's anionic dyes was proposed to quantitate SMV in the pure form and the pharmaceutical capsule. The measurements were carried out at their corresponding $\lambda$ max. SMV-ion-pairs have acceptable stability for a long period of time, up to $120 \mathrm{~min}$. The association's high values constant, $5.5 \times 10^{3}, 1.1 \times 10^{5}, 1.8 \times 10^{4}$, and $9.3 \times 10^{2} \mathrm{~L} \mathrm{~mol}^{-1}$ for BTB, BCP, BCG, and BXB, respectively, indicate the stability of the ion-pairs. Negative values of $\Delta \mathrm{G}^{\circ}$, indicate the spontaneity of the reaction. Linearity is up to $60,35,60$, and $67 \mu \mathrm{g} \mathrm{mL} \mathrm{m}^{-1}$ for BTB, BCP, BCG, and BXB, respectively. Molar absorptivity and low Sandell sensitivity reflect the good and high sensitivity of the methods. The correlation coefficients $\left(\mathrm{r}^{2}\right)$ are 0.9989-0.9999 indicating good linearity of the calibration curves. Low relative standard deviation (RSD\%) values, 0.15-1.43, indicate the proposed methods' precision. Therefore, the method depended on the utilization of unsophisticated and inexpensive equipment in parallel with the operator care and eco-concern to defeat the drawbacks of the methods needing further extraction and a few modern techniques restrictions.

\section{Funding}

This research received no external funding.

\section{Acknowledgments}

This research has no acknowledgment.

\section{Conflicts of Interest}

The authors declare no conflict of interest.

\section{References}

1. Vanwelkenhuysen, I.R.; Timmerman, P.; Verhaeghe, T. Determination of simeprevir: a novel, hepatitis C protease inhibitor in human plasma by high-performance liquid chromatography-tandem mass spectrometry. J. Chrom. B. 2014, 958, 43-47, http://dx.doi.org/10.1016/j.jchromb.2014.02.028.

2. Childs-Kean, L.M.; Hand, E.O. Simeprevir and sofosbuvir for treatment of chronic hepatitis c infection. Clin. Ther. 2015, 37, 243-267, https://doi.org/10.1016/j.clinthera.2014.12.012.

3. Cisneros, L. Hepatitis C virus: worldwide epidemic. Proc. West. Pharmacol. Soc. 2006, 49, 6-13.

4. Ariaudo, A.; Favata, F.; De Nicolo, A.; Simiele, M.; Paglietti, L.; Boglione, L.; Cardellino, C.S.; Carcieri, C.; Di Perri, G.; D'Avolio, A. A UHPLC-MS/MS method for the quantification of direct antiviral agents simeprevir, daclatasvir, ledipasvir, sofosbuvir/GS-331007, dasabuvir, ombitasvir and paritaprevir, together 
with ritonavir, in human plasma. J. Pharm. Biomed. Anal. 2016, 125, 369-375, http://doi.org/10.1016/j.jpba.2016.04.031.

5. Engy, M.E. Hepatitis C Virus Infection in Egypt: Current Situation and Future Perspective. J. High Institute Public Health 2019, 49, 1-9, http://doi.org/10.21608/JHIPH.2019.29460.

6. Rosenquist, A.; Samuelsson, B.; Johansson, P.O.; Cummings, M.D.; Lenz, O.; Raboisson, P.; Simmen, K.; Vendeville, S.; de Kock, H.; Nilsson, M.; Horvath, A.; Kalmeijer, R.; de la Rosa, G.; Beumont-Mauviel, M. Discovery and development of simeprevir (TMC435), a HCV NS3/4A protease inhibitor. J. Med. Chem. 2014, 57, 1673-1693, https://doi.org/10.1021/jm401507s.

7. Philip, V.K.; Annika, K.; Silvio, S.; Hanspeter, S.; Volker, T. Coronavirus biology and replication: implications for SARS-CoV-2. Nature Reviews Microbiology 2020, http://doi.org/10.1038/s41579-02000468-6.

8. Leon, C.; Julian, D.D.; Mike, G.C.; David, A.J.; Kylie, M.W. The FDA-approved drug ivermectin inhibits the replication of SARS-CoV-2 in vitro. Antiviral Res. 2020, 178, https://doi.org/10.1016/j.antiviral.2020.104787.

9. Sanne, B.; Huib, H.R.; Lucas, J.M.B.; Tonja, P.; Arno, L.W.V.; Joep, B.; Hans, C.; Frank, J.M.K.; Marvin, E.T. Translation and Replication Dynamics of Single RNA Viruses. Cell 2020, 183, 1930-1945.e23, https://doi.org/10.1016/j.cell.2020.10.019.

10. NIH Conference, Pathogenesis, Natural History, Treatment and Prevention of Hepatitis C. Ann. Internal Med. 2000, 132, 296-305, https://doi.org/10.7326/0003-4819-132-4-200002150-00008.

11. Jyh-Jou, C.; Hung-Da, T.; Pei-Lun, L.; Hsing-Tao, K.; Ming-Jen, S.; Chun-Ta, C.; Tang-Wei, C.; Hsu-Ju, K.; Na-Mi, L.; Li-Ching, W.; Chuan, L. High prevalence of genotype 6 hepatitis C virus infection in Southern Taiwan using Abbott genotype assays. J. Formosan Med. Association 2020, 119, 413-419, https://doi.org/10.1016/j.jfma.2019.07.021.

12. Radwa, R.E.; Ahmed, M.G.; Hosam, Z. Dissection of two drug-targeted regions of Hepatitis C virus subtype 4a infecting Egyptian patients. Virus Genes. 2020, 56, 564-581,http://doi.org/10.1007/s11262-020-01776-y.

13. Nannetti, G.; Pagni, S.; Parisi, S.G.; Alberti, A.; Loregian, A.; Palu, G. Development of a simple HPLC-UV method for the determination of the hepatitis C virus inhibitor simeprevir in human plasma. J. Pharm. Biomed. Anal. 2016, 121, 197-203, http://dx.doi.org/10.1016/j.jpba.2016.01.019.

14. Dahari, H.; Canini, L.; Graw, F.; Uprichard, S.L.; Araujo, E.S.; Penaranda, G.; Coquet, E.; Chiche, L.; Riso, A.; Renou, C.; Bourliere, M.; Cotler, S.J.; Halfon, P. HCV kinetic and modeling analyses indicate similar time to cure among sofosbuvir combination regimens with daclatasvir, simeprevir or ledipasvir. J. Hepatol. 2016, 64, 1232-1239, https://doi.org/10.1016/j.jhep.2016.02.022.

15. Eric, L.; Fred, P.; Julio, A.G.; Maria, B.; Greet, B.; Ann, V.; Pieter, V.R.; Donghan, L.; Leen, V.; Veerle, V.E.; Mohamed, G. Simeprevir, daclatasvir, and sofosbuvir for hepatitis C virus-infected patients: Longterm follow-up results from the open-label, Phase II IMPACT study. Health Sci. Rep. 2020, 3, http://doi.org/10.1002/hsr2.145 .

16. Ho, S.L.; Kenrie, P.Y.H.; Hei-Ming, L.; Khadija, S.K.; Simranjeet, K.; Zhongqi, L.; Anthony, K.N.C.; Hayley, H.C.; Ka, C.N.; John, C.W.H.; Yu, W.C.; Bowen, M.; Peter, M.C.; Donghyuk, S.; Kaidao, W.; Kuen-Phon, W.; Ivan, D.; Po-Huang, L.; Zhong, Z.; Francis, K.L.C.; David, S.C.H.; Vincent, C.T.M.; KamBo, W.; Ho, K.; Wei, S.A.; Michael, C.W.C.; Wai-Lung, N. Simeprevir suppresses SARS-CoV-2 replication and synergizes with remdesivir. Biorxiv 2020, https://doi.org/10.1101/2020.05.26.116020.

17. Mohamed, S.H.; Issa, Y.M.; Salim, A.I. Simultaneous quantification of simeprevir sodium: a hepatitis C protease inhibitor in binary and ternary mixtures with sofosbuvir and/or ledipasvir utilizing direct and $\mathrm{H}-$ point standard addition strategies. Spectrochim. Acta A: Mol. Biomol. Spectrosc. 2019, 210, 290-297, https://doi.org/10.1016/j.saa.2018.07.017.

18. Ossama, A.A.; Mohamed, A.E.; Mohamed Hassan, A.F.; Mahmoud, E.; Rehab, B.; Ahmed, K.; Shaimaa, S.; Manal Saad, N.; Sherief, A.-E. Outcomes of Treatment and Predictors of Response to Sofosbuvir Plus Simeprevir in Hepatitis C Virus with Genotype-4 Infection. Infectious Disorders - Drug Targets 2020, 20, 389-395, https://doi.org/10.2174/1871526519666181218104600.

19. Therapeutic Goods Administration. Janssen-Cilag Pty Ltd, AusPAR Olysio/Janssen Simeprevir (as sodium), 2014, https://www.tga.gov.au/node/283535.

20. Attia, K.A.M.; El-Abasawi, N.M.; El-Olemy, A.; Serag, A. Different spectrophotometric methods applied for the analysis of simeprevir in the presence of its oxidative degradation product: Acomparative study. Spectrochim. Acta A: Mol. Biomol. Spectrosc. 2018, 190, 1-9, https://doi.org/10.1016/j.saa.2017.08.066.

21. Kumar, B.R.; Subrahmanyam, K.V. A new validated RP-HPLC method for the simultaneous determination of simeprevir and sofosbuvir in pharmaceutical dosage form. Indo. Am. Pharm. Res. 2016, 6, 4508-4520.

22. Mohammed, B.S.; Hamad, A.E.; Derayea, S.M. Stress stability study of simeprevir, a hepatitis C virus inhibitor, using feasible TLC-spectrodensitometry: application to pharmaceutical dosage form and human plasma. RSC Adv. 2020, 10, https://doi.org/10.1039/d0ra01172j.

23. Attia, K.A.M.; El-Abasawi, N.M.; El-Olemy, A.; Serag, A. Stability-indicating HPLC-DAD Method for the Determination of Simeprevir. Anal. Chem. Let. 2017, 7, 43-51, https://doi.org/10.1080/22297928.2017.1287004. 
24. Youssef, A.F.A.; Issa, Y.M.; Nabil, K.M. Development and Validation of a New Method for the Determination of Anti-hepatitis C Agent Simeprevir in Human Plasma using HPLC with Fluorescence Detection. Current. Anal. Chem. 2020, 16, https://doi.org/10.2174/1573411015666181217121619.

25. Hamad, A.E.; Mohammed, B.S.; Derayea, S.M.; El-Malla, S.F. Micelle sensitized synchronous spectrofluorimetric approaches for the simultaneous determination of simeprevir and ledipasvir: Application to pharmaceutical formulations and human plasma. Spectrochim. Acta A: Mol. Biomol. Spectrosc. 2020, 239, https://doi.org/10.1016/j.saa.2020.118471.

26. Derayea, S.M.; El Hamd, M.A.; Ali, S.; Samir, E. Microenvironment improvement protocol for the sensitive spectrofluorimetric determination of an hepatitis $\mathrm{C}$ virus antiviral (Simeprevir): application to human plasma. Luminescence 2019, 35, 1-7, https://doi.org/10.1002/bio.3739.

27. Mohammed, B.S.; Hamad, A.E.; El-Malla, S.F.; Derayea, S.M. Sensitive spectrofluorimetric assay based on micelle enhanced protocol for the determination of hepatitis $\mathrm{C}$ antiviral agent (simeprevir): Application to dosage form and human plasma. Microchemical J 2020, 152, https://doi.org/10.1016/j.microc.2019.104372.

28. Harvey, A.E.; Manning, D.L. Spectrophotometric Methods of Establishing Empirical Formulas of Colored Complexes in Solution. J. Am. Chem. Soc. 1950, 72, 4488-4493. https://doi.org/10.1021/ja01166a044.

29. Benesi, A.H.; Hildebrand, J.H. A Spectrophotometric Investigation of the Interaction of Iodine with Aromatic Hydrocarbons. J. Am. Chem. Soc. 1949, 71, 2703-2707, https://doi.org/10.1021/ja01176a030.

30. Dempster, A.J. A new Method of Positive Ray Analysis. Phys. Rev. 1918, 11, https://doi.org/10.1103/PhysRev.11.316.

31. Sevgi, T.U.; Elmali, F.T. Spectrophotometric method for the determination, validation, spectroscopic and thermal analysis of diphenhydramine in pharmaceutical preparation. Spectrochim. Acta. A: Mol. Biomol. Spectrosc. 2010, 77, 324-329, https://doi.org/10.1016/j.saa.2010.05.031.

Monakhova, Y.B.; Mattias, K.; Kuballa, T.; Lachenmeier, D.W. Determination of the purity of pharmaceutical reference materials by $1 \mathrm{H}$ NMR using the standardless PULCON methodology. J. Pharm. Biomed. Anal. 2014, 100, 381-386, https://doi.org/10.1016/j.jpba.2014.08.02

32. Attia, A.K.; Abdel-Moety, M.M.; Abdel-Hamid, S.G. Thermal analysis study of antihypertensive drug doxazosin mesylate. Arab. J. Chem. 2012, 10, 334-338, https://doi.org/10.1016/j.arabjc.2012.08.006.

33. Goudaa, A.A.; El-Shafey, Z.; Hossny, N.; El-Azzazy, R. Spectrophotometric determination of hyoscine butylbromide and famciclovir in pure form and in pharmaceutical formulations. Spectrochim. Acta. A: Mol. Biomol. Spectrosc. 2008, 70, 785-792, https://doi.org/10.1016/j.saa.2007.09.010.

34. Sanchez-Rasero, F. Stoichiometry, Ringbom optimal range, and other parameters for the copper(I)bathocuproine complex. Microchemical J 1981, 26, 418-425, https://doi.org/10.1016/0026-265X(81)90120X. 